RESEARCH REPORT

\title{
Life events and the risk of low back and neck/shoulder pain of the kind people are seeking care for: results from the MUSIC- Norrtälje case-control study
}

\section{Eva Skillgate, Eva Vingård, Malin Josephson, Töres Theorell, Lars Alfredsson}

See end of article for authors' affiliations

Correspondence to: Mrs E Skillgate, Division of Cardiovascular

Epidemiology, Institute of Environmental Medicine, Karolinska Institutet, Box 210, SE-171 77 Stockholm Sweden; eva.skillgate@ki.se

Accepted 7 August 2006

\begin{abstract}
Objective: To expand the knowledge about the occurrence of life events, and how they affect the risk of low back and neck/shoulder pain.

Design: A population-based case-control study.

Setting: Men and women 20-59-years old, living in and not working outside the municipality of Norrtälje, Sweden, from November 1993 to November 1997.

Participants: Cases $(n=1$ 148) were defined as all subjects from the study base who sought healthcare for a new episode of low back and/or neck/shoulder pain by any of the care givers in the municipality. Controls $(n=1700)$ were selected as a stratified random sample from the study base, considering sex and age. Study subjects were interviewed about life events and critical life changes. Critical life changes were defined as events that brought about a marked psychosocial change. Odds ratios (ORs) associated with different numbers of life events or critical life changes were calculated.

Results: Having experienced at least two life events during the preceding 5 years was associated with an increased risk of neck/shoulder pain $(O R=1.6,95 \% \mathrm{Cl} 1.1$ to 2.4). At least two critical life changes were associated with an increased risk of neck/shoulder pain $(O R=1.9,95 \% \mathrm{Cl} 1.3$ to 2.7). In general, no associations were observed in relation to risk of low back pain.

Conclusion: Life events and critical life changes are of importance for the risk of neck/shoulder pain of the kind that people are seeking care for. The study provides useful information for clinical practice and for future aetiological research on neck/shoulder pain.
\end{abstract}

M ost people experience, changes of great importance in their psychosocial situation of some time during their life. Such events or changes, clearly defined in time and distinguishable from chronic difficulties and hassles, are defined as "life events" in the literature. ${ }^{1-3}$

Pain with associated disability from low back and neck/ shoulder occurs commonly and constitutes an extensive health problem. ${ }^{45}$ It has been increasingly established that psychological and psychosocial factors play significant roles in the aetiology of chronic as well as acute back and neck pain..$^{5-8}$

Previously published studies have observed that life events or changes may constitute important stressors, and that they play a role in the onset of cardiovascular disorders, mental disorders, fibromyalgia and symptoms of joints and muscle disorders. ${ }^{23}$ 9${ }^{11}$ The role of life events or changes in the onset of back and neck pain, in itself, is not fully understood. A relationship between life events and low back pain has been observed in several studies ${ }^{12-16}$ but not in others. ${ }^{17-21}$ Research on life events in relationship with neck pain is scarce.

In life events research, different methods for exposure assessment have been used. One method was developed by Holmes and Rahe, the Social Readjustment Rating scale. It has the underpinning idea, based on Selye's stress theory, that a non-specific accumulation of life changes, regardless of whether they are positive or negative, during a short period of time, would increase vulnerability to illness. The required adaptation is an important component in the illness aetiology of illness, via the sympatho-adreno-cortical systems, according to this theory. ${ }^{22}$

Brown and Harris developed the Life Event and Difficulties Schedule, a semi-structured interview form, designed to assess the effect of events from a sociological point of view. ${ }^{3}$ The extensive interview was designed to determine whether the event was a chronic difficulty or a life change and whether it was markedly threatening or not. In the MUSIC-Norrtälje Study, an interview technique measuring several aspects of life events, including "critical life changes" based on the theories of Holmes and Rahe as well as Brown and Harris, was used. A "critical life change" is defined as a life event that brings about a marked psychological or psychosocial change for the study subject.

The overall aim of the present study was to expand the knowledge about the occurrence of life events and how they affect the risk of low back and neck/shoulder pain. Specific aims were to investigate the role of the number of life events and critical life changes; the role of the arena in which the event took place; and the role of time that has passed since the event took place for the risk of low back and neck/shoulder pain, respectively.

\section{METHODS}

Study design and study population

The present report is a sub study of the MUSIC-Norrtälje Study: a population-based case-control study on determinants and consequences of low back and neck/shoulder disorders. The study population $(\mathrm{n}=17000)$ comprised all men and women 20-59-years old, living in and not working outside the municipality of Norrtälje, Sweden, during the study period November 1993 to November 1997.

\section{Case ascertainment}

A case was defined as a subject from the study base who sought care or treatment for a new episode of low back pain or neck/ shoulder pain. A "new episode" meant not having sought care 
for these problems during the preceding 6 months. Cases were identified by any of the 75 known care givers in the municipality. None of the invited care givers refused to participate. The care givers were doctors, naprapaths, chiropractors and physiotherapists, as well as alternative care givers such as osteopaths, massage therapists and homeopaths. The care givers were asked to contact the MUSIC secretariat when they met a suitable case. The secretariat then contacted the case as soon as possible for an appointment (this took place within 2 months, most commonly within 1-2 weeks). In all, 709 cases with low back pain, 352 with neck/shoulder pain and 87 with low back and neck/shoulder pain were included.

\section{Selection of controls}

Controls were selected as a stratified random sample from the study base, with considerations made for sex and age (in 5-year intervals) by means of the population register that was continuously updated. One control that had not sought care for low back or neck/shoulder pain during the preceding 6 months was chosen for each case. If a selected control was unable or refused to enter the study, he or she was not replaced. If there was space in the investigation schedule, we chose another control within the same 5-year span as the control before this. The proportion of selected controls that participated in the study was about $70 \%$ (1700).

\section{Assessments and classification of exposure}

The measurements in the MUSIC Study have been described in detail elsewhere and only the parts relevant for the present report are described below. ${ }^{23} 24$

At the MUSIC secretariat, all subjects filled out selfadministered questionnaires, underwent a clinical examination, and were interviewed about individual and environmental factors considered to be potential risk factors for low back and/ or neck/shoulder pain. The interview about psychological and psychosocial factors was performed by one of seven behavioural scientists and lasted for about an hour for each study subject. The interviewers did not know whether they interviewed a case or a control subject. Regular group meetings were held to keep the inter-rater reliability constant over time. ${ }^{25}$

The first part of the interview concerned the present situation and, after this part, retrospective data for the previous 5 years were collected, including information on life events at work and outside work. The interview technique, measuring several aspects of life events including "critical life changes", was based on a previously validated questionnaire by Theorell et al. ${ }^{26}$ The two main questions in the interview were: "Looking back five years, have there been any life events or changes in your work or workplace during that period?" and "Looking back five years, have there been any life events or changes concerning your life outside work during that period?" The questions were open and the study subject was asked to specify the life events and to state when they took place.

Life events that brought about a psychological or psychosocial lasting change for the study subject, such as lasting changes in social relationships, in household participation, in family relationships, in support at work and in use of skills, were classified as "critical life changes". The two most outstanding changes within the two arenas "at work" and "outside work", respectively, were noted. The classification of critical life changes was the result of a discussion between the study subject and the interviewer.

\section{Comparisons and statistical analysis}

For each study subject, the number of reported life events and critical life changes, respectively, was calculated. In the analysis, subjects classified into different categories regarding reported life events or critical life changes ("exposed") were compared with a reference category ("unexposed"). The reference category was made up of subjects who had experienced no or one life event in the preceding 5 years. When analysing critical life changes in different "arenas", the reference category was made up of subjects with no critical life changes.

Exposed subjects were compared with unexposed subjects regarding the risk of low back and neck/shoulder pain, respectively, by calculating an odds ratio (OR) with 95\% confidence interval (CI) by means of logistic regression analysis. ORs were adjusted for age (dichotomised to $<45$ and $\geqslant 45$-years of age) and sex. An additional number of factors that had turned out to be related to the outcomes in previous reports from the MUSIC-Norrtälje Study were considered with regard to their potential confounding effect in the analyses. ${ }^{24} 27$ The potential confounders were introduced in the model, one at a time, and the amount of change in the coefficient of the exposure term was examined. If it changed considerably (around $10 \%$ or more), the variable was considered a confounder and added to the model. ${ }^{29}$ Potential confounders were (all on a dichotomised basis) the following: earlier episodes of neck/shoulder or low back pain, depression treated by a doctor, work with hands over head $\geqslant 30 \mathrm{~min} /$ day repetitive hand and finger movements at least 2 days/week, computer work during at least half of the working day, no permanent salary, night work or shifts with night work, working full-time, working alone, job strain, low support at work, working with vibrating tools at least $20 \%$ of the day, and socioeconomic status. None of these factors turned out to be confounders, and were thus not included in the final regression model. The estimated ORs can be interpreted as relative risks (RRs) as the study was population-based and the controls were a random sample from the study base. ${ }^{30}$

In addition, we investigated potential effect modification by time spans and arenas, respectively, by means of stratified analysis. Thus, the relationship between number of life events and outcomes were calculated for different time spans concerning when during the preceding 5 years the event took place. Similarly, ORs associated with number of life events were calculated for different arenas - that is, whether the event took place outside work or at work.

In the analyses, cases with concurrent pain in the neck/ shoulder and low back $(n=87)$ were treated both as neck/ shoulder pain cases and low back pain cases.

All calculations were performed using the statistical program Intercooled STATA V.8.0.

\section{RESULTS}

Table 1 shows the characteristics of subjects, by disease status.

\section{Frequency of life events and critical life changes in the study base}

Life events outside work were more frequent than life events at work. About $63 \%$ of all controls reported at least one event and about $14 \%$ at least three events at work, whereas $89 \%$ reported at least one event and $45 \%$ at least three events outside work during the preceding 5 years. With regard to critical life changes, $56 \%$ of all controls had experienced at least one change at work, whereas $71 \%$ had experienced at least one change outside work during the preceding 5 years. Women reported more life events outside work than men, but there was no difference between women and men concerning the number of life events at work. Table 2 shows the proportion of subjects who reported different specific life events among controls as well as among cases. 
Table 1 Characteristics of subjects, by disease status (low back pain, neck/shoulder pain and low back pain, and neck/shoulder pain

\begin{tabular}{lcrrl}
\hline Characteristics & Controls & LBP & NSP & LBP and NSP \\
\hline Women (n) & 984 & 390 & 251 & 63 \\
Men (n) & 716 & 319 & 101 & 24 \\
Total (n) & 1700 & 709 & 352 & 87 \\
Mean age (years) & 40 & 40 & 39 & 40 \\
Blue-collar workers (\%) & 58 & 63 & 57 & 74 \\
Job strain (\%) & 4 & 6 & 7 & 9 \\
Earlier episodes of LBP or NSP (\%) & 45 & 70 & 70 & 84 \\
Depression, treated for now or earlier (\%) & 5 & 6 & 7 & 15 \\
\hline
\end{tabular}

LBP, low back pain; NSP, neck/shoulder pain; LBP and NSP, low back pain and neck/shoulder pain.

\section{Life events and critical life changes as potential risk factors}

The ORs of neck/shoulder pain and low back pain, associated with different numbers of life events and critical life changes, respectively, during the preceding 5 years are displayed in table 3. Having experienced at least two life events was associated with an increased risk of neck/shoulder pain $(\mathrm{OR}=1.6,95 \% \mathrm{CI} 1.1$ to 2.4$)$, and experience of at least two critical life changes was associated with an increased risk of neck/shoulder pain (OR $=1.9,95 \%$ CI 1.3 to 2.7). A doseresponse relationship was not observed. No association between life events or critical life changes, respectively, and risk of low back pain was observed.

When women and men were analysed separately, no systematic differences were observed regarding the estimated ORs of neck/shoulder pain and low back pain, respectively.

There were no systematic differences in ORs, depending on when during the preceding 5 years the event took place (table 4).

The ORs of neck/shoulder pain and low back pain, respectively, associated with different numbers of critical life changes on different "arenas" (outside work and at work) are displayed in Table 5. An association between at least two critical life changes at work and low back pain was found. Regarding the risk of neck/shoulder pain, a relative comparison showed that at least one critical life change at work implied a higher risk increase than at least one critical life change outside work $(\mathrm{OR}=1.4,95 \% \mathrm{CI} 1$ to 2 ; not shown in table).

\section{DISCUSSION \\ Main results}

Two or more life events or critical life changes, respectively, experienced during the preceding 5 years were observed to be associated with an increased risk of neck/shoulder pain, whereas, in general, no associations were observed in relation to risk of low back pain. The increased risks were most pronounced regarding critical life changes and especially changes experienced at work, where an increased risk for low back pain was observed as well. There were no systematic differences in the observed ORs between men and women, nor did the number of years within the 5 -year period since the event took place influence the results.

\section{Methodological considerations}

A strength of the study is that the experience of life events was assessed by a careful interview, as suggested in a review of studies of life events and illness. ${ }^{31}$

Another strength is the definition of the study base as adult inhabitants living in, and not working outside, the municipality, and the cooperation with all known care givers in the

Table 2 Proportion of subjects reporting life events that took place 5 years preceding the interview, by disease status (low back pain, neck/shoulder pain and low back pain and neck/ shoulder pain

\begin{tabular}{|c|c|c|c|c|}
\hline Type of life event & Controls (\%) & LBP (\%) & NSP (\%) & LBP and NSP (\%) \\
\hline $\begin{array}{l}\text { Altered work conditions/retirement } \\
\text { for a relative or oneself }\end{array}$ & 60 & 60 & 63 & 60 \\
\hline $\begin{array}{l}\text { Had a child, adoption of a child or } \\
\text { parental leave }\end{array}$ & 31 & 28 & 31 & $24^{*}$ \\
\hline Moved home (oneself, family or children) & 44 & 48 & 48 & 45 \\
\hline $\begin{array}{l}\text { Entered a new permanent relationship with a } \\
\text { partner }\end{array}$ & 13 & $16^{*}$ & $17^{*}$ & $17^{*}$ \\
\hline Divorce (or equivalent) & 12 & 13 & 14 & 14 \\
\hline $\begin{array}{l}\text { Close relative in a crisis, taking } \\
\text { care of a close relative or } \\
\text { death of a relative }\end{array}$ & 40 & 40 & $49^{*}$ & $46^{*}$ \\
\hline Experienced disease or trauma & 9 & 10 & $13^{*}$ & $16^{*}$ \\
\hline Changed workplace, profession or employer & 36 & 38 & $54^{*}$ & $47^{*}$ \\
\hline $\begin{array}{l}\text { Changes in the workplace } \\
\text { such as reduction of staff, more or fewer tasks, } \\
\text { more responsibilities, new techniques }\end{array}$ & 37 & 34 & $47^{*}$ & $30^{*}$ \\
\hline $\begin{array}{l}\text { From working alone to workmates, from } \\
\text { workmates to working alone, from } \\
\text { employed to self-employed, from } \\
\text { self-employed to employed }\end{array}$ & 8 & 10 & 10 & 10 \\
\hline Other events outside work & 24 & 22 & 26 & 28 \\
\hline Other events at work & 32 & 29 & $38^{*}$ & 31 \\
\hline
\end{tabular}

LBP, low back pain; NSP; neck/shoulder pain; LBP and NSP; low back pain and neck/shoulder pain *Significantly different from controls $(p<0.05)$. 


\begin{tabular}{|c|c|c|c|c|c|c|c|}
\hline \multirow[b]{3}{*}{ Case/control } & \multicolumn{7}{|c|}{ Number of life events } \\
\hline & \multicolumn{2}{|c|}{$0-1^{*}$} & \multicolumn{2}{|l|}{2} & \multicolumn{2}{|l|}{3} & \multirow{2}{*}{$\begin{array}{l}4- \\
\mathrm{ORT}(95 \% \mathrm{Cl})\end{array}$} \\
\hline & $\overline{\mathrm{OR}}$ & Case/control & $\mathrm{OR}+(95 \% \mathrm{Cl})$ & Case/control & $\overline{\mathrm{OR}+}(95 \% \mathrm{Cl})$ & Case/control & \\
\hline $\begin{array}{l}\text { Neck/shoulder } \\
46 / 326 \\
\text { Low back } \\
144 / 326\end{array}$ & $\begin{array}{l}\text { er } \\
1 \\
1\end{array}$ & $\begin{array}{l}71 / 301 \\
146 / 301\end{array}$ & $\begin{array}{l}1.6(1.1 \text { to } 2.4) \\
1.1(0.8 \text { to } 1.5)\end{array}$ & $\begin{array}{l}80 / 299 \\
163 / 299\end{array}$ & $\begin{array}{l}1.8(1.2 \text { to } 2.7) \\
1.2(0.9 \text { to } 1.6)\end{array}$ & $\begin{array}{l}242 / 774 \\
343 / 774\end{array}$ & $\begin{array}{l}1.6(1.2 \text { to } 2.0) \\
1.0(0.8 \text { to } 1.2)\end{array}$ \\
\hline & \multicolumn{7}{|c|}{ Number of critical life changes } \\
\hline & \multicolumn{2}{|l|}{$0-1^{*}$} & \multicolumn{2}{|l|}{2} & \multicolumn{2}{|l|}{3} & 4- \\
\hline Case/control & ORt & Case/control & $\begin{array}{l}\text { ORt } \\
(95 \% \mathrm{Cl})\end{array}$ & Case/control & $\begin{array}{l}\text { ORt } \\
(95 \% \text { Cl) }\end{array}$ & Case/control & $\begin{array}{l}\text { ORt } \\
(95 \% \mathrm{Cl})\end{array}$ \\
\hline $\begin{array}{l}\text { Neck/ } \\
\text { shoulder } \\
46 / 326 \\
\text { Low back } \\
144 / 326\end{array}$ & 1 & $\begin{array}{l}130 / 440 \\
232 / 440\end{array}$ & $\begin{array}{l}1.9(1.3 \text { to } 2.7) \\
1.2(0.9 \text { to } 1.5)\end{array}$ & $\begin{array}{l}87 / 271 \\
122 / 271\end{array}$ & $\begin{array}{l}2.2(1.5 \text { to } 3.3) \\
1.0(0.8 \text { to } 1.4)\end{array}$ & $\begin{array}{l}75 / 216 \\
106 / 216\end{array}$ & $\begin{array}{l}2.2(1.4 \text { to } 3.4) \\
1.1(0.8 \text { to } 1.5)\end{array}$ \\
\hline
\end{tabular}

area, even complementary and alternative ones, implying that a great majority of the subjects who had sought healthcare for low back and/or neck/shoulder pain during 4 years were included. We identified 1148 cases among a population of approximately 17000 persons. This corresponds to an incidence of two cases per 100 person years. A few cases might have travelled outside the municipality for care and some cases might have refused to or have not been offered to participate. In summary, we believe that a high proportion of eligible cases was identified.

To be able to study "new" episodes of back and neck pain, subjects that had sought care during the preceding 6 months were excluded. Information on previous back and neck pain was collected, and we took that into consideration in the analyses. It turned out that back and neck pain earlier in life, for more than seven days in a row, was a strong predictor of low back pain ( $\mathrm{OR}=3.6$; 95\% CI 3.0 to 4.4 ) and neck/shoulder pain

Table 4 OR of neck/shoulder pain and low back pain, respectively, together with $95 \% \mathrm{Cl}$ associated with the number of life events during the preceding 5 years, by different time spans

\begin{tabular}{|c|c|c|c|c|}
\hline \multirow{3}{*}{$\begin{array}{l}\text { Number of years } \\
\text { before inclusion in the } \\
\text { study }\end{array}$} & \multicolumn{4}{|c|}{ Number of life events } \\
\hline & \multicolumn{2}{|l|}{$0-1^{*}$} & \multicolumn{2}{|l|}{$2-$} \\
\hline & Case/control & OR† & $\begin{array}{l}\text { Case/ } \\
\text { control }\end{array}$ & OR+ $(95 \% \mathrm{Cl})$ \\
\hline \multicolumn{5}{|l|}{$0-2 \ddagger$} \\
\hline Neck/shoulder & $44 / 296$ & 1 & $80 / 271$ & $\begin{array}{l}1.8(1.1 \text { to } \\
2.7)\end{array}$ \\
\hline Low back & $129 / 296$ & 1 & $124 / 271$ & $\begin{array}{l}1.1(0.8 \text { to } \\
1.4)\end{array}$ \\
\hline \multicolumn{5}{|l|}{$3-5 \S$} \\
\hline Neck/shoulder & $44 / 296$ & 1 & $65 / 219$ & $\begin{array}{l}1.9 \text { (1.2 to } \\
2.9)\end{array}$ \\
\hline Low back & $129 / 296$ & 1 & $96 / 219$ & $\begin{array}{l}1.0(0.7 \text { to } \\
1.4)\end{array}$ \\
\hline
\end{tabular}

*Reference category; 0-1 life events during the preceding five years. †Adjusted for age and sex.

$\ddagger$ Two or more life events the preceding $0-2$ years and no life events $3-5$ years before inclusion in the study compared with the reference category. $\S$ Two or more life events the preceding 3-5 years and no life events $0-2$ years before inclusion in the study compared with the reference category.
( $\mathrm{OR}=4.4 ; 95 \% \mathrm{CI} 3.5$ to 5.6 ), but was not a confounder in the analysis of life events as a risk factor. When subjects with earlier neck/shoulder pain were excluded from the analyses, life events were still observed to be related to the occurrence of neck/shoulder pain, adding more validity to the observed relationship.

Recall bias might be considered a limitation of this study . If cases had tended to recall life events more willingly than the controls, the ORs would tend to be overestimates. Given the disparity of the results regarding neck/shoulder and low back pain, respectively, it is highly unlikely that recall bias could explain the observed association between life events and neck/ shoulder pain, as we have no reason to expect recall to differ between low back cases and neck/shoulder cases.

We acknowledge the difference between seeking care for pain on the one hand, and the occurrence of pain on the other. It is conceivable that life events might influence care-seeking behaviour and thereby give rise to selection bias. Our data suggests such an influence is not the case, however, as there was no association between life events and seeking care for low back pain, which could be expected under this hypothesis. Ijzelenberg et al have studied work-related factors associated with musculoskeletal symptoms and healthcare use, respectively, and found that these were quite similar. ${ }^{32}$

No systematic differences were observed in ORs depending on when during the preceding 5 years the event took place. One might suspect under-reporting of events that occurred several years ago, compared with events that occurred recently, but there was no selective reporting of recent events, given that the true incidence of life events in the population was constant over 5 years.

Confounding does not seem to be an appreciable problem in this study as only age turned out to be a confounder among several potential confounders, including depression, job strain (a major source of psychological distress at work) and musculoskeletal disorders. But we cannot exclude residual confounding from factors not measured-for example psychological distress outside work.

In summary, we believe that the observed relationship between life events and a new episode of neck/shoulder pain of the kind people are seeking care for is real and not totally explained by bias. 
Table 5 OR of neck/shoulder pain and low back pain, respectively, together with $95 \% \mathrm{Cl}$ associated with number of critical life changes during the preceding 5 years, by different "arenas"

\begin{tabular}{|c|c|c|c|c|c|c|}
\hline & \multicolumn{6}{|c|}{ Number of critical life changes } \\
\hline & \multicolumn{2}{|l|}{$0^{*}$} & \multicolumn{2}{|l|}{1} & \multicolumn{2}{|l|}{$2-$} \\
\hline & Case/control & ORt & Case/control & ORt $(95 \% \mathrm{Cl})$ & Case/control & $\mathrm{OR+}(95 \% \mathrm{Cl})$ \\
\hline \multicolumn{7}{|l|}{ Outside work } \\
\hline Neck/shoulder & $39 / 252$ & 1 & $60 / 346$ & $1.1(0.7$ to 1.7$)$ & $45 / 159$ & $1.6(1.0$ to 2.6$)$ \\
\hline $\begin{array}{l}\text { Low back } \\
\text { At work§ }\end{array}$ & $101 / 251$ & 1 & $164 / 346$ & $1.2(0.9$ to 1.6$)$ & $80 / 159$ & $1.3(0.9$ to 1.9$)$ \\
\hline Neck/shoulder & $39 / 252$ & 1 & $48 / 175$ & $1.8(1.1$ to 2.8$)$ & $27 / 84$ & $2.1(1.2$ to 3.6$)$ \\
\hline $\begin{array}{l}\text { Low back } \\
\text { In total }\end{array}$ & $101 / 251$ & 1 & $70 / 175$ & $1.0(0.7$ to 1.4$)$ & $52 / 84$ & $1.6(1.0$ to 2.4$)$ \\
\hline Neck/shoulder & $39 / 252$ & 1 & $108 / 521$ & $1.3(0.9$ to 2.0$)$ & $292 / 927^{* *}$ & $1.8(1.3$ to 2.6$)$ \\
\hline Low back & $101 / 251$ & 1 & $234 / 521$ & $1.1(0.8$ to 1.5$)$ & $461 / 927^{* *}$ & $1.2(0.9$ to 1.6$)$ \\
\hline
\end{tabular}

*Reference category. No critical life changes at work during or outside work the preceding 5 years.

†Adjusted for age and sex.

‡Respectively one and at least two critical life changes outside work during but no critical life changes at work the preceding 5 years compared with the reference category.

§Respectively one and at least two critical life changes at work, but no critical life changes outside work during the preceding 5 years compared with the reference category.

- Respectively one and at least two critical life changes at work and/or outside work during the preceding 5 years.

${ }^{* *}$ The number of exposed cases/controls is higher than the sum of exposed cases/controls in the categories outside work and at work, since critical life changes in this category may have happened at work and/or outside work.

\section{What is already known}

- Life events play a role in the onset of different disorders, but their role in the onset of back and neck pain is not fully understood. Results are conflicting regarding life events and low back pain, and research about life events and neck/shoulder pain is scarce.

\section{What this study adds}

- Life events and critical life changes are of importance for the risk of neck/shoulder pain, whereas in general no associations are observed in relation to risk of low back pain. Researchers should consider life events as a potential confounder in aetiological studies of other contributing risk factors for neck/shoulder pain. With regard to clinical practice, the results might offer patients who have experienced life events a possible explanation for their neck/shoulder pain.

\section{The results in comparison with other research}

The association between life events and neck/shoulder pain has scarcely been investigated before. Results from earlier studies of life events and low back pain are conflicting, probably because of the different study designs, different definitions of exposure and case definitions. Moreover, most of them have used selfadministered life event questionnaires.

Some studies have shown the importance of rating the experience of the event as positive or negative. During the interview in our study, the interviewer noted the positive/ negative value of the events. However, due to the complex nature of most life events and also due to a questionable reliability in this part of the interview, it was not meaningful to report results stratified by experience.

The potential mechanisms behind the association between life events and risk of neck/shoulder pain are not clear, but there are several possible theories. Selye's stress theory, the general adaptation theory, stated that a non-specific accumulation of life changes during a short period of time would increase vulnerability to illness. The effort to adapt to a dramatic change would arouse the sympatho-adreno-cortical systems according to Selye. ${ }^{2}$

Experimental studies have shown that mental stress results in an increased muscle tension in the neck and shoulder region. ${ }^{33}$ Several explanatory models explain the correlation between the increased muscle tension and musculoskeletal disorders. ${ }^{34-37}$ We have no explanation for the disparity in associations between low back and neck/shoulder pain found in this study. As per our knowledge, research on the correlation between stress and tension in muscles in the lower back area has not been carried out. There is some evidence of an effect of psychosocial factors at work on low back pain, but we have found no evidence of an effect of psychosocial factors in private life on low back pain in the literature. ${ }^{38}$

Life events may be looked upon as psychological stress. Psychological risk factors were in a review shown to be more important in the development of pain and disability than are most biomedical and biomechanical factors. Among psychosocial factors were stress, distress or anxiety, cognitive functioning and pain behaviour, all found to be significant predictors..$^{5-8}$

\section{CONCLUSIONS}

Life events and critical life changes seem to be of importance for the risk of neck/shoulder pain of the kind that people are seeking care for, whereas their associations with regard to risk of low back pain are more uncertain.

\section{Acknowledgements}

The authors gratefully acknowledge all the care givers in Norrtälje; the administration in the Norrtälje section of the County Council; the advisory board to the MUSIC network; and all the collaborators for their excellent work. The authors would also like to thank Lena W Holm, Karolinska Institutet, for valuable comments on the manuscript.

\section{Authors' affiliations}

Eva Skillgate, Lars Alfredsson, Institute of Environmental Medicine, Division of Cardiovascular Epidemiology, Karolinska Institutet, Stockholm, Sweden

Eva Skillgate, Skandinaviska Naprapathögskolan, Stockholm, Sweden Eva Vingård, Malin Josephson, Department of Medical Sciences, Occupational and Environmental Medicine, Uppsala Universitet, Uppsala, Sweden 
Eva Vingård, Malin Josephson, Section of Personal Injury Prevention, Karolinska Institutet, Stockholm, Sweden

Töres Theorell, Karolinska Institutet and National Institute for Psychosocial Factors and Health, Stockholm, Sweden

Lars Alfredsson, Stockholm Center for Public Health, Stockholm County Council, Stockholm, Sweden

Funding: This study was supported by grants from the Swedish Council for Work Life Research, the Stockholm County Council, and the HealthCare Science Postgraduate School, Karolinska Institutet, Sweden.

Competing interests: None.

Ethical approval: The present study was approved by the Ethics Committee of the Karolinska Institutet, Sweden.

\section{REFERENCES}

1 Theorell T, Alfredsson L, Westerholm P, et al. Coping with unfair treatment at work-What is the relationship between coping and hypertension in middle-aged men and women? An epidemiological study of working men and women in Stockholm (the WOLF Study). Psychother Psychosom 2000;69:86-94

2 Cooper CL. Handbook of stress, medicine and health. Boca Raton: CRC Press, 1996:137-58

3 Brown GW, Harris T. Social origins of depression: a study of psychiatric disorders in women. London: Tavistock, 1978.

4 SBU. Sjukskrivning - orsaker, konsekvenser och praxis. En systematisk litteraturöversikt. Stockholm: The Swedish Council on Technology Assessment in Health Care, 2003.

5 Jonsson E, Nachemson AL. Neck and back pain; the scientific evidence of causes, diagnosis and treatment. Philadelphia: Lippincott, Williams \& Wilkins, 2000.

6 Linton SJ. Early identification and intervention in the prevention of musculoskeletal pain. Am J Ind Med 2002;41:433-442.

7 Linton SJ. A review of psychological risk factors in back and neck pain. Spine 2000;25:1148-56.

8 Hoogendoorn WE, Bongers PM, de Vet HC, et al. Psychosocial work characteristics and psychological strain in relation to low-back pain. Scand J Work Environ Health 2001;27:258-67.

9 Anderberg UM, Marteinsdottir I, Theorell T, et al. The impact of life events in female patients with fibromyalgia and in female healthy controls. Eur Psychiatry 2000;15:295-301.

10 Dohrenwend BS, Dohrenwend BP. Stressful life events: their nature and effects. New York: John Wiley \& Sons, 1974.

11 Theorell T, Lind E, Flodérus B. The relationship of disturbing life-changes and emotions to the early development of myocardial infraction and other serious illnesses. Int J Epidemiol 1975;4:281-93.

12 Craufurd DI, Creed F, Jayson MI. Life events and psychological disturbance in patients with low-back pain. Spine 1990;15:490-4.

13 Feuerstein M, Sult S, Houle M. Environmental stressors and chronic low back pain: life events, family and work environment. Pain 1985;22:295-307.

14 Lampe A, Sollner W, Krismer M, et al. The impact of stressful life events on exacerbation of chronic low-back pain. J Psychosom Res 1998:44:555-63.

15 Rose HJ. The lives of patients before presentation with pain in the neck or back. J R Coll Gen Pract 1975;25:771-2.

16 Yip YB, Ho SC, Chan SG. Socio-psychological stressors as risk factors for low back pain in Chinese middle-aged women. J Adv Nurs 2001;36:409-16.
17 Jensen J. Life events in neurological patients with headache and low back pain (in relation to diagnosis and persistence of pain). Pain 1988;32:47-53.

18 Leavitt F, Garron DC, Bieliauskas LA. Stressing life events and the experience of low back pain. J Psychosom Res 1979;23:49-55.

19 Nwuga VC. Relationship between low back pain and life-stressing events among Nigerian patients. J Trop Med Hyg 1985;88:17-20.

20 Theorell T, Emlund N. On physiological effects of positive and negative life changes-a longitudinal study. J Psychosom Res 1993;37:653-9.

21 Lampe A, Doering S, Rumpold G, et al. Chronic pain syndromes and their relation to childhood abuse and stressful life events. J Psychosom Res 2003;54:361-7.

22 Holmes TH, Rahe RH. The Social Readjustment Rating Scale. J Psychosom Res 1967;11:213-18.

23 Vingard E, Mortimer M, Wiktorin C, et al. Seeking care for low back pain in the general population: a two-year follow-up study. Results from the MUSICNorrtalje Study. Spine 2002;27:2159-65.

24 Wigaeus Tornqvist E, Kilbom A, Vingard E, et al. The influence on seeking care because of neck and shoulder disorders from work-related exposures. Epidemiology 2001;12:537-5.

25 Waldenstrom $M$, Josephson $M$, Persson $C$, et al. Interview reliability for assessing mental work demands. J Occup Health Psychol 1998:3:209-16.

26 Theorell T, Michélsen H, Nordemar R, et al. Levnadshändelser och copingmönster i Stockholmsundersökningen 1 ln: Hagberg M, Hogstedt C, eds. Stockholmsundersökningen 1. Stockholm: Music Books A, 1991.

27 Mortimer M, Wiktorin C, Pernol G, et al. Sports activities, body weight and smoking in relation to low-back pain: a population-based case-referent study. Scand J Med Sci Sports 2001;11:178-184.

28 Vingard E, Alfredsson L, Hagberg $M$, et al. To what extent do current and past physical and psychosocial occupational factors explain care-seeking for low back pain in a working population? Results from the Musculoskeletal Intervention Center-Norrtalje Study. Spine 2000;25:493-500.

29 Rothman KJ. Epidemiology. An introduction. New York: Oxford University Press, 2002.

30 Miettinen O. Estimability and estimation in case-referent studies. Am J Epidemiol 1976;103:226-35.

31 Paykel ES. Methodological aspects of life events research. J Psychosom Res 1983;27:341-52.

32 lizelenberg W, Burdorf A. Risk factors for musculoskeletal symptoms and ensuing health care use and sick leave. Spine 2005;30:1550-56.

33 Lundberg U, Kadefors R, Melin B, et al. Psychophysiological stress and EMG activity of the trapezius muscle. Int J Behav Med 1994;1:354-70.

34 Schleifer LM, Ley R. End-tidal PCO2 as an index of psychophysiological activity during VDT data-entry work and relaxation. Ergonomics 1994; $37: 245-54$

35 Johansson H, Sojka P. Pathophysiological mechanisms involved in genesis and spread of muscular tension in occupational muscle pain and in chronic musculoskeletal pain syndromes: a hypothesis. Med Hypotheses 1991;35:196-203

36 Knardahl S. Psychophysiological mechanisms of pain in computer work: the blood vessel-nociceptor interaction hypothesis. Work Stress 2002;16:179-89.

37 Sjogaard G, Lundberg U, Kadefors R. The role of muscle activity and mental load in the development of pain and degenerative processes at the muscle cell level during computer work. Eur J Appl Physiol 2000;83:99-105.

38 Hoogendoorn WE, van Poppel MN, Bongers PM, et al. Systematic review of psychosocial factors at work and private life as risk factors for back pain. Spine 2000;25:2114-25 